\title{
Elazığ İlinde Arpalarda Görülen Yaprak Hastalıkları
}

\author{
Ișı SARAÇ ${ }^{1},{ }^{\star} A z i z$ KARAKAYA², Arzu ÇELIK OĞUZ² \\ ${ }^{1}$ Bingöl Üniversitesi, Ziraat Fakültesi, Bitki Koruma Bölümü, Bingöl, Türkiye \\ ${ }^{2}$ Ankara Üniversitesi, Ziraat Fakültesi, Bitki Koruma Bölümü, Dıșkapı, Ankara, Türkiye \\ *Corresponding author e-mail (Sorumlu yazar e-posta): karakaya@agri.ankara.edu.tr \\ Geliș Tarihi (Received): 08.11.2018 Kabul Tarihi (Accepted): 07.03.2019
}

\begin{abstract}
Öz
2018 yılının Mayıs ve Haziran aylarında Elazığ ilinin merkez ilçe, Karakoçan, Palu, Arıcak, Kovancılar, Keban, Ağın, Baskil, Sivrice ve Maden ilçelerinin arpa yetiștirilen alanlarında sürveyler yapılmıș ve arpa bitkilerinde görülen yaprak hastalıkları belirlenmiștir. Arpa bitkilerinde Drechslera teres f. maculata ve Drechslera teres f. teres tarafından olușturulan arpa ağbenek hastalığının nokta ve ağ formları, Rhynchosporium secalis tarafından olușturulan arpa yaprak lekesi hastalığı, Erysiphe graminis f. sp. hordei tarafından olușturulan külleme hastalığı, Puccinia hordei tarafından olușturulan kahverengi pas (yaprak pası) hastalığı ve Drechslera graminea tarafından olușturulan arpa çizgili yaprak lekesi hastalığı tespit edilmiștir. Elazığ ilinde incelenen 42 arpa tarlasının 23'ünde Drechslera teres f. maculata, 21'inde Drechslera teres f. teres, 19'unda Rhynchosporium secalis, 9'unda Erysiphe graminis f. sp. hordei, 15' inde Puccinia hordei, 11 'inde ise Drechslera graminea etmenleri tarafından meydana getirilen hastalıklar görülmüştür. Arpa ağbenek hastalığının nokta formu (Drechslera teres f. maculata) Keban ve Maden ilçeleri dıșında incelenen bütün ilçelerde görülmüștür. Arpa ağbenek hastalığının ağ formu (Drechslera teres f. teres) Arıcak, Sivrice ve Maden ilçeleri dıșında kalan diğer ilçelerde görülmüștür. Rhynchosporium secalis tarafından olușturulan arpa yaprak lekesi hastalığı Ağın, Baskil ve Sivrice ilçeleri dıșında kalan bütün ilçelerde görülmüștür. Erysiphe graminis f. sp. hordei tarafından meydana getirilen külleme hastalığı Palu, Arıcak ve Sivrice ilçeleri dıșındaki ilçelerde görülmüștür. Puccinia hordei tarafından olușturulan arpa kahverengi pası hastalığı Arıcak, Sivrice, Ağın ve Maden ilçeleri dıșındaki ilçelerde görülmüștür. Drechslera graminea tarafından olușturulan arpa çizgili yaprak lekesi hastalığı Arıcak, Keban, Ağın, Sivrice ve Maden ilçeleri dıșındaki ilçelerde görülmüștür. Drechslera teres f. maculata tarafından olușturulan arpa ağbenek hastalığının nokta formu ve Drechslera teres f. teres tarafından olușturulan arpa ağbenek hastalığının ağ formu en fazla tarlada görülen hastalıklar olurken bunları Rhynchosporium secalis tarafından olușturulan arpa yaprak lekesi hastalığı takip etmiștir. Hastalık görülen tarlalarda hastalıklı bitkilerin görülme yüzdeleri Drechslera teres f. maculata ve Rhynchosporium secalis için 1-20 arasında, Drechslera teres f. teres için 1-25 arasında, Erysiphe graminis f. sp. hordei ve Drechslera graminea için 1-30 arasında, Puccinia hordei için ise 1-45 arasında değișmiștir. Hastalık șiddeti $R$. secalis tarafından olușturulan arpa yaprak lekesi için 3-7 arasında değișirken diğer hastalıklar için 3-5 arasında değișmiștir. Bu hastalıklara karșı mücadele metotları geliștirilmelidir.
\end{abstract}

Anahtar Kelimeler: Elazığ, Arpa, Hordeum vulgare, arpa yaprak hastalıkları

\section{Determination of the Barley Leaf Diseases Occurring in Elazığ Province of Turkey}

\section{Abstract}

Barley growing areas of Elazığ province of Turkey were surveyed during the period of May and June of 2018 and barley leaf diseases were determined. Surveys included Elazığ central district and Karakoçan, Palu, Arıcak, Kovancılar, Keban, Ağın, Baskil, Sivrice and Maden districts. Following diseases were recorded; spot form of net blotch caused by Drechslera teres f. maculata, net form of net blotch caused by Drechslera teres f. teres, barley scald disease caused by Rhynchosporium secalis, powdery mildew caused by Erysiphe graminis f. sp. hordei, barley brown (leaf) rust caused by Puccinia hordei and barley stripe disease caused by Drechslera graminea. A total of 42 barley fields were inspected. Drechslera teres f. teres, Drechslera teres f. maculata, Rhynchosporium secalis, Erysiphe graminis f. sp. hordei, Puccinia hordei and Drechslera graminea were observed in 23, 21, 19, 9, 15 and 11 fields, respectively. Spot form 
of net bloch was observed in all districts with the exception of Keban and Maden districts. Net form of net blotch was not observed in Arıcak, Sivrice and Maden districts. Scald was not observed in Ağın, Baskil and Sivrice districts. Powdery mildew was not observed in Palu, Arıcak and Sivrice districts. Brown (leaf) rust was not observed in Arıcak, Sivrice, Ağın and Maden districts. Barley stripe was not observed in Arıcak, Keban, Ağın, Sivrice and Maden districts. Spot form of net blotch and net form of net blotch were the most commonly encountered diseases. Scald followed these diseases. Disease incidence percentages of Drechslera teres f. maculata, Rhynchosporium secalis, Drechslera teres f. teres, Erysiphe graminis f. sp. hordei, Drechslera graminea and Puccinia hordei were ranged between 1-20, 1-20, 1-25, 1-30, 1-30 and $1-45$, respectively. Disease severity values of scald caused by $R$. secalis was ranged between 3-7. Disease severity values of other diseases were ranged between 3-5. Control methods should be implemented regarding these diseases.

Keywords: Elazığ, Barley, Hordeum vulgare, barley leaf diseases

\section{Giriș}

Arpa (Hordeum vulgare L.), soğuk ve kurak șartlara dayanıklı olup besin maddesi bakımından zayıf topraklarda dahi yetiștirilebilen önemli bir kültür bitkisidir (Mathre, 1982). Yem değeri yüksek bir tahıl olan arpa daha çok hayvan beslenmesinde kullanılmaktadır. Buna ek olarak malt sanayiinde ve insan beslenmesinde de kullanılır (Geçit, 2016; Geçit ve ark., 2009; Kün, 1996).

Arpa Türkiye tarımında en önemli bitkilerden birisidir. Anadolu'da binlerce yıldır ekimi yapılan arpa, ülkemiz tarımında buğdaydan sonra en çok ekimi yapılan tahıldır. Türkiye arpanın gen merkezleri içinde yer almaktadır (Kün, 1996).

Arpa bitkisi değișik biyotik ve abiyotik hastalık etmenlerinden etkilenmektedir (Mathre, 1982). Verimi ve kaliteyi düșüren bu hastalıkların tespiti ve gerekli tedbirlerin alınması önem tașımaktadır. Ülkemizde yapılan çalıșmalarda aralarında Drechslera teres, Rhynchosporium secalis, Drechslera graminea, Puccinia hordei, Erysiphe graminis f. sp. hordei gibi patojenlerin olduğu çok sayıda hastalık etmenine rastlanmıştır (Çelik ve Karakaya, 2015; Ertürk ve ark., 2018; illgen ve ark., 2017; Özdemir ve ark., 2017). Bu çalıșmada Elazığ ilinde yetiștirilen arpa bitkilerinde görülen fungal hastalıklar tespit edilmiștir.

\section{Materyal ve Yöntem}

2018 yılının Mayıs ve Haziran aylarında Elazığ ilinin merkez ilçe, Karakoçan, Palu, Arıcak, Kovancılar, Keban, Ağın, Baskil, Sivrice ve Maden ilçelerinin arpa yetiștirilen alanlarında sürveyler yapılmıș ve arpa bitkilerinde görülen yaprak hastalıkları belirlenmiștir. Sürveyler bitkilerin çiçeklenme, süt olum ve sarı olum devreleri arasında geçekleștirilmiștir. Sürvey çalıșmalarında sistematik örnekleme yöntemi kullanılmıștır (Aktaș, 2001). Her 1-30 kilometrede durularak her bir tarlada en az 100 bitki incelenmiștir. Toplam 42 adet arpa tarlası incelenmiștir. Bitkiler makroskobik olarak incelenmiș ve hastalıklar tarlada teșhis edilmiștir (Mathre, 1982; Zillinsky, 1983). Hastalık șiddetlerinin belirlenmesinde Saari ve Prescott (1975) tarafından geliștirilen 1-9 ıskalası kullanılmıștır. Ortalama yaygınlığın ve șiddetin hesaplanmasında hastalık görülen ve görülmeyen tarlalar birlikte değerlendirilmiștir. Sürvey yapılan ilçeler, her ilçede ekilen alan (dekar), incelenen tarla adedi ve incelenen alan yüzdesi Tablo 1'de verilmiștir. Az miktarda arpa ekim alanına sahip olan Alacakaya ilçesinden örnek alınmamıștır.

\section{Bulgular ve Tartıșma}

Elazığ ilinde yapılan sürveylerde arpa bitkilerinde Drechslera teres f. maculata ve Drechslera teres f. teres tarafından olușturulan arpa ağbenek hastalığının nokta ve ağ formları, Rhynchosporium secalis tarafından olușturulan arpa yaprak lekesi hastalığı, Erysiphe graminis f. sp. hordei tarafından olușturulan külleme hastalığı, Puccinia hordei tarafından olușturulan kahverengi pas (yaprak pası) hastalığı ve Drechslera graminea tarafından olușturulan arpa çizgili yaprak lekesi hastalığı tespit edilmiștir (Çizelge 2). Elazığ ilinde incelenen 
Çizelge 1. Elazığ ilinde 2018 yılında arpa yaprak hastalıkları sürveyi yapılan ilçeler, her ilçede ekilen alan (da), sürvey yapılan alan, incelenen tarla adedi ve incelenen alan yüzdeleri

Table 1. Districts of Elazığ province of Turkey where the barley leaf diseases survey was carried out and barley planting areas of each district (decares), da surveyed areas, numbers of inspected fields and percentages of areas inspected in 2018

\begin{tabular}{lcccc}
\hline İlçeler & $\begin{array}{c}\text { Ekilen alan } \\
\text { (TüiK, 2017) (da) }\end{array}$ & $\begin{array}{c}\text { Sürvey yapılan } \\
\text { alan (da) }\end{array}$ & $\begin{array}{c}\text { Incelenen } \\
\text { tarla (adet) }\end{array}$ & $\begin{array}{c}\text { İncelenen alan } \\
\text { yüzdesi (\%) }\end{array}$ \\
\hline Karakoçan & 37.709 & 430 & 15 & 1.14 \\
Palu & 10.674 & 115 & 5 & 1.08 \\
Arıcak & 2.816 & 45 & 2 & 1.60 \\
Kovancılar & 84.499 & 115 & 5 & 0.14 \\
Merkez & 219.292 & 140 & 5 & 0.06 \\
Keban & 7.040 & 55 & 2 & 0.78 \\
Ağın & 18.396 & 30 & 1 & 0.16 \\
Baskil & 34.149 & 145 & 5 & 0.42 \\
Sivrice & 9.514 & 30 & 1 & 0.32 \\
Maden & 5.038 & 30 & 1 & 0.60 \\
Alacakaya & 1.038 & 0 & 0 & 0 \\
\hline
\end{tabular}

42 arpa tarlasının 23'ünde Drechslera teres f. maculata, 21'inde Drechslera teres f. teres, 19'unda Rhynchosporium secalis, 9'unda Erysiphe graminis f. sp. hordei, 15'inde Puccinia hordei, 11'inde ise Drechslera graminea etmenleri tarafından meydana getirilen hastalıklar görülmüştür.

Hastalıkgörülen tarlalarda hastalıklı bitkilerin görülme yüzdeleri Drechslera teres f. maculata ve Rhynchosporium secalis için 1-20 arasında, Drechslera teres f. teres için 1-25 arasında, Erysiphe graminis f. sp. hordei ve Drechslera graminea için 1-30 arasında, Puccinia hordei için ise 1-45 arasında değișmiștir. Hastalık șiddeti $R$. secalis tarafından olușturulan arpa yaprak lekesi için 3-7 arasında değișirken diğer hastalıklar için 3-5 arasında değișmiștir.

Arpa ağbenek hastalığının nokta formu (Drechslera teres f. maculata) Keban ve Maden ilçeleri dıșında incelenen bütün ilçelerde görülmüștür (Çizelge 3). Hastalık fazla sayıda tarlada görülmesine karșılık hastalanan bitki sayısı yüzdesi düșük olarak bulunmuștur (\%1 - \%4.46). Arpa ağbenek hastalığının ağ formu (Drechslera teres f. teres) Arıcak, Sivrice ve Maden ilçeleri dıșında kalan diğer ilçelerde görülmüștür. Bu hastalığın ilçelerde yaygınlık oranları \%1.06-\%7.6 arasında değișmiștir. Ağbenek hastalığının ağ formunun yaygınlığı en yüksek oranda Kovancılar ilçesinde

Çizelge 2. 2018 yılında Elazığ ilinde yapılan sürveylerde arpa bitkilerinde görülen hastalık etmenleri, ortalama hastalık yaygınlıkları, hastalıkla bulașık tarla sayıları, hastalıklı bitki görülme yüzde aralığı ve hastalık șiddetleri. Hastalık șiddetlerinin hesaplanmasında Saari ve Prescott (1975) tarafından geliștirilen 1-9 skalası kullanılmıștır.

Table 2. The causal agents of diseases, mean disease incidences, numbers of fields with diseases, ranges of percentages of occurrences of diseases and disease severity values in Elazığ province of Turkey in 2018. For determining the severity of diseases, a 1-9 scale developed by Saari and Prescott (1975) was used.

\begin{tabular}{lcccc}
\hline Arpa hastalıkları & $\begin{array}{c}\text { Ortalama } \\
\text { hastalık } \\
\text { yaygınlığı }\end{array}$ & $\begin{array}{c}\text { Hastalıkla } \\
\text { bulașık tarla } \\
\text { sayısı }\end{array}$ & $\begin{array}{c}\text { Hasta bitki } \\
\text { görülme yüzdesi } \\
\text { aralığı }\end{array}$ & $\begin{array}{c}\text { Hastalık șiddeti } \\
\text { (ortalama hastalık } \\
\text { șiddeti) }\end{array}$ \\
\hline Drechslera teres f. maculata & 2.57 & 23 & $1-20$ & $3-5(4.30)$ \\
Drechslera teres f. teres & 2.45 & 21 & $1-25$ & $3-5(3.95)$ \\
Rhynchosporium secalis & 2.16 & 19 & $1-20$ & $3-7(4.15)$ \\
Erysiphe graminis f. sp. hordei & 1.23 & 9 & $1-30$ & $3-5(3.66)$ \\
Puccinia hordei & 3.19 & 15 & $1-45$ & $3-5(3.53)$ \\
Drechslera graminea & 1.38 & 11 & $1-30$ & - \\
\hline
\end{tabular}


Çizelge 3. Elazığ ilinde yapılan sürveylerde arpa bitkilerinde ilçelere göre incelenen tarla sayıları, hastalık görülen tarla sayıları, hastalıkların yaygınlık ve șiddetleri. Hastalık șiddetlerinin hesaplanmasında Saari ve Prescott (1975) tarafından geliștirilen 1-9 skalası kullanılmıștır.

Table 3. Inspected barley fields in each district, numbers of diseased fields, incidence and severity values of the diseases in Elazığ province of Turkey. For determining the severity of diseases, a 1-9 scale developed by Saari and Prescott (1975) was used.

\begin{tabular}{|c|c|c|c|c|c|c|c|c|c|c|}
\hline \multirow[b]{2}{*}{ İlçe } & \multirow{2}{*}{$\begin{array}{l}\text { Tarla } \\
\text { sayısı }\end{array}$} & \multicolumn{3}{|c|}{ Drechslera teres f. maculata } & \multicolumn{3}{|c|}{ Drechslera teres f. teres } & \multicolumn{3}{|c|}{ Rhynchosporium secalis } \\
\hline & & Tarla & $\begin{array}{l}\text { Yaygınlık } \\
(\%)\end{array}$ & Șiddet & Tarla & $\begin{array}{l}\text { Yaygınlık } \\
(\%)\end{array}$ & Șiddet & Tarla & $\begin{array}{l}\text { Yaygınlık } \\
(\%)\end{array}$ & Șiddet \\
\hline Karakoçan & 15 & 11 & 4.46 & $3-5(3.9)$ & 4 & 1.06 & $3-5(4)$ & 6 & 1.73 & $3-7(4.6)$ \\
\hline Palu & 5 & 3 & 1.6 & $5(5)$ & 4 & 4.2 & $5(5)$ & 3 & 2.6 & $3-5(3.6)$ \\
\hline Arıcak & 2 & 1 & 2.5 & $5(5)$ & - & - & - & 2 & 12.5 & $5(5)$ \\
\hline Kovancılar & 5 & 2 & 2 & $5(5)$ & 4 & 7.6 & $3-5(4.5)$ & 2 & 1.2 & $3-5(4)$ \\
\hline Merkez & 5 & 1 & 1 & $3(3)$ & 3 & 1.8 & $3(3)$ & 3 & 2.6 & $3-5(3.6)$ \\
\hline Keban & 2 & - & - & - & 2 & 3 & $3(3)$ & 2 & 1.5 & $3(3)$ \\
\hline Ağın & 1 & 1 & 2 & $5(5)$ & 1 & 5 & $3(3)$ & - & - & - \\
\hline Baskil & 5 & 3 & 1.8 & $\begin{array}{l}3-5 \\
(3.7)\end{array}$ & 3 & 1.6 & $3-5(4.3)$ & - & - & - \\
\hline Sivrice & 1 & 1 & 2 & $5(5)$ & - & - & - & - & - & - \\
\hline Maden & 1 & - & - & - & - & - & - & 1 & 5 & $5(5)$ \\
\hline Alacakaya & 0 & 0 & - & - & 0 & - & - & 0 & - & - \\
\hline \multirow{2}{*}{ İlçe } & \multirow{2}{*}{$\begin{array}{l}\text { Tarla } \\
\text { sayısı }\end{array}$} & \multicolumn{3}{|c|}{$\begin{array}{c}\text { Erysiphe graminis f. sp. } \\
\text { hordei }\end{array}$} & \multicolumn{3}{|c|}{ Puccinia hordei } & \multicolumn{3}{|c|}{ Drechslera graminea } \\
\hline & & Tarla & $\begin{array}{l}\text { Yaygınlık } \\
(\%)\end{array}$ & Șiddet & Tarla & $\begin{array}{l}\text { Yaygınlık } \\
(\%)\end{array}$ & Șiddet & Tarla & $\begin{array}{l}\text { Yaygınlık } \\
(\%)\end{array}$ & Şiddet \\
\hline Karakoçan & 15 & 2 & 0.13 & $3(3)$ & 4 & 1.33 & $3-5(3.5)$ & 2 & 0.26 & - \\
\hline Palu & 5 & - & - & - & 4 & 1.8 & $3-5(3.5)$ & 1 & 0.06 & - \\
\hline Arıcak & 2 & - & - & - & - & - & - & - & - & - \\
\hline Kovancılar & 5 & 1 & 0.6 & $3(3)$ & 2 & 11 & $5(5)$ & 2 & 0.4 & - \\
\hline Merkez & 5 & 1 & 0.2 & $3(3)$ & 2 & 4.4 & $3(3)$ & 2 & 0.6 & - \\
\hline Keban & 2 & 1 & 0.5 & $3(3)$ & 1 & 10 & $3(3)$ & - & - & - \\
\hline Ağın & 1 & 1 & 1 & $3(3)$ & - & - & - & - & - & - \\
\hline Baskil & 5 & 2 & 8 & $3-5(4)$ & 2 & 1.4 & $3(3)$ & 4 & 9.6 & - \\
\hline Sivrice & 1 & - & - & - & - & - & - & - & - & - \\
\hline Maden & 1 & 1 & 5 & 5 (5) & - & - & - & - & - & - \\
\hline Alacakaya & 0 & 0 & - & - & 0 & - & - & 0 & - & - \\
\hline
\end{tabular}

görülmüștür (\%7.6). Rhynchosporium secalis tarafından olușturulan arpa yaprak lekesi hastalığı Ağın, Baskil ve Sivrice ilçeleri dıșında kalan bütün ilçelerde görülmüștür. Bu hastalığın en yüksek yaygınlık oranı Kovancılar ilçesinde tespit edilmiștir (\%12.5). Erysiphe graminis f. sp. hordei tarafından meydana getirilen külleme hastalığı Palu, Arıcak ve Sivrice ilçeleri dıșındaki ilçelerde görülmüștür. Külleme hastalığının yaygınlığı Baskil ilçesinde \%8, Maden ilçesinde \%5 olarak görülürken diğer ilçelerde düșük olarak görülmüștür. Puccinia hordei tarafından olușturulan arpa kahverengi pası hastalığı Arıcak, Sivrice, Ağın ve Maden ilçeleri dıșındaki ilçelerde görülmüștür. Arpa kahverengi pası hastalığı hastalığının yaygınlığı Kovancılar ilçesinde \%11, Keban ilçesinde $\% 10$, merkez ilçede \%4.4 olarak görülürken diğer ilçelerde daha düșük olarak görülmüștür. Drechslera graminea tarafından olușturulan arpa çizgili yaprak lekesi hastalığı Arıcak, Keban, Ağın, Sivrice ve Maden ilçeleri dıșındaki ilçelerde görülmüștür. Arpa çizgili yaprak lekesi hastalığının yaygınlığı Baskil ilçesinde \%9.6 
olarak bulunurken diğer ilçelerde daha düșük olarak görülmüștür.

Elazığ ilinde Drechslera teres f. maculata tarafından olușturulan arpa ağbenek hastalığının nokta formu ve Drechslera teres f. teres tarafından olușturulan arpa ağbenek hastalığının ağ formu en fazla tarlada görülen hastalıklar olurken bunları Rhynchosporium secalis tarafından olușturulan arpa yaprak lekesi hastalı̆̆ı takip etmiștir. Arpa bitkilerinde Elazığ ilinde görülen diğer hastalıklar etmeni Erysiphe graminis f. sp. hordei olan külleme hastalığı, etmeni Puccinia hordei olan kahverengi pas hastalı̆ı̆ ve etmeni Drechslera graminea olan arpa çizgili yaprak lekesi hastalığı olarak bulunmuștur. Bu hastalıklar ülkemizde yaygın olarak görülen hastalıklar olup diğer araștıııcılar tarafından Türkiye'nin değișik bölgelerinden rapor edilmișlerdir (Akan, 2006; Aktaș, 1987, 1997; Çelik ve Karakaya, 2015; Ertürk ve ark., 2018; İlgen ve ark., 2017; Karakaya ve ark., 2014, 2016; Mamluk ve ark., 1997; Özdemir ve ark., 2017; Yıldırım ve ark., 1999).

Çelik ve Karakaya (2015) Eskişehir ilinde 2012 yılında yaptıkları sürveyde arpa yaprak hastalıklarından ağbenek (Drechslera teres), çizgili yaprak lekesi ( $D$. graminea), kahverengi pas (Puccinia hordei), Rhynchosporium yaprak lekesi (Rhynchosporium secalis), külleme (Erysiphe graminis f. sp. hordei), sap kısmında kara pas (Puccinia graminis f. sp. tritici) ve bașak hastalıklarından ise rastık türleri (Ustilago spp.) belirlemișlerdir. Bu hastalıklardan $D$. teres tarafından meydana getirilen arpa ağbenek leke hastalığı ve $R$. secalis tarafından meydana getirilen arpa yaprak lekesi hastalığı en yaygın hastalıklar olarak bulunmuștur. Bizim çalıșmamızda da bu iki hastalık en yaygın hastalıklar olarak göze çarpmıștır. Özdemir ve ark.'nın 2017 yılında yaptıkları çalışmada Kırıkkale ilinde arpa tarlalarında Drechslera teres f. maculata, Drechslera teres f. teres, Drechslera graminea, Rhynchosporium commune (eski ismi: $R$. secalis) (Zaffarano ve ark., 2011), Erysiphe graminis f. sp. hordei, Puccinia striiformis, Puccinia hordei ve Puccinia graminis f. sp. tritici tarafından olușturulan hastalıklara rastlamıșlardır. Bu çalıșmada da araștııııılar ağbenek hastalığı ve arpada Rhynchosporium yaprak lekesi hastalıklarını en yaygın hastalıklar olarak bulmușlardır. Benzer sonuçlar Ankara'nın Çubuk ve Bala ilçelerinde de görülmüștür (Ertürk ve ark., 2018; İlgen ve ark., 2017). Özellikle bu hastalıklara karșı mücadele metotları geliștirilmelidir.

\section{Sonuç}

Elazığ ilinde arpa bitkilerinde Drechslera teres f. maculata ve Drechslera teres f. teres tarafından olușturulan arpa ağbenek hastalığının nokta ve ağ formları, Rhynchosporium secalis tarafından olușturulan arpa yaprak lekesi hastalığı, Erysiphe graminis f. sp. hordei tarafından olușturulan külleme hastalığı, Puccinia hordei tarafından olușturulan kahverengi pas (yaprak pası) hastalığı ve Drechslera graminea tarafından olușturulan arpa çizgili yaprak lekesi hastalığı tespit edilmiștir. Drechslera teres f. maculata tarafından olușturulan arpa ağbenek hastalığının nokta formu ve Drechslera teres f. teres tarafından olușturulan arpa ağbenek hastalı̆ııın ağ formu en fazla tarlada görülen hastalıklar olurken bunları Rhynchosporium secalis tarafından olușturulan arpa yaprak lekesi hastalığı takip etmiștir. Bu hastalıklara karșı mücadele metotları geliștirilmelidir.

\section{Kaynaklar}

Akan, K., Çetin, L., Albostan, S., Düșünceli, F., \& Mert, Z. (2006). İç Anadolu'da görülen önemli tahıl ve nohut hastalıkları. Tarla Bitkileri Merkez Araștırma Enstitüsü Dergisi 15 (1-2): 29-48.

Aktaș, H. (1987). Untersuchungen Uber Die Physiologische Variationen von Drechslera teres (Sacc.) Shoemaker on der Mittelaratolien angebauten Gersten Und die Feststellung der Reaktionen der Gerstensorten gegen diesen Erreger. Journal of Turkish Phytopathology 16: 53-65.

Aktaș, H. (1997). Untersuchungen über die Netzfleckenkrankheiten (Drechslera teres Shoem. f. sp. teres Smedeg. D. teres Shoem. f. sp. maculata Smedeg.) an Gerste. Journal of Turkish Phytopathology 26 (1): 17-22.

Aktaș, H. (2001). Önemli hububat hastalıkları ve sürvey yöntemleri. T.C. Tarım ve Köyișleri Bakanlığı. Tarımsal Araștırmalar Genel Müdürlüğü. Bitki Sağlığı Araștırmaları Daire Bașkanlığı. Ankara.

Çelik, E., \& Karakaya, A. (2015). Eskișehir ili arpa ekim alanlarında görülen fungal yaprak ve bașak hastalıklarının görülme sıklıklarının ve yoğunluklarının belirlenmesi. Bitki Koruma Bülteni 55 (2): 157-170. 
Ertürk, H., Karakaya A., \& Çelik Oğuz, A. (2018). Leaf diseases occurring on barley plants in Bala district of Ankara province, Turkey. Ecological Life Sciences 13 (4): 204-207.

Geçit, H.H., Çiftçi, C.Y., Emeklier, Y., İkincikarakaya, S.Ü., Adak, M.S., Kolsarıcı, ... Kendir, H. (2009). Tarla Bitkileri. Ankara Üniversitesi, Ziraat Fakültesi Yayınları, Yayın no: 1569, Ders Kitabı: 521. Ankara.

Geçit, H.H. (2016). Serin Iklim Tahılları (Buğday, Arpa, Yulaf, Triticale). Ankara Üniversitesi Ziraat Fakültesi Yayınları, Yayın No:1640. Ankara.

İlgen, M.Z., Karakaya, A., \& Çelik Oğuz, A. (2017). Leaf diseases occurring on barley and wheat fields in Çubuk district of Ankara, Turkey. Works of the Faculty of Agriculture and Food Sciences University of Sarajevo. Vol. XLII, 67/2, 210-215.

Karakaya, A., Mert, Z., Çelik Oğuz, A., \& Çetin, L. (2016). Distribution of barley stripe disease in Central Anatolia, Turkey. Selcuk Journal of Agriculture and Food Sciences 30 (2): 58-61.

Karakaya, A., Mert, Z., Çelik Oğuz, A., Azamparsa, M.R., Çelik, E., Akan, K., \& Çetin, L. (2014). Current status of scald and net blotch diseases of barley in Turkey. IWBLD - 1st International Workshop on Barley Leaf Diseases. 03-06 June 2014, Salsomaggiore Terme, Italy.

Kün, E. (1996). Tahıllar-1 (Serin İklim Tahılları) 3. baskı. Ankara Üniversitesi Ziraat Fakültesi Yayınları, Yayın No: 1451, Ankara.
Mamluk, O.F., Çetin, L., Braun, H.J., Bolat, N., Bertschinger, L., Makkouk, K.M., ... Düșünceli, F. (1997). Current status of wheat and barley diseases in the Central Anatolia Plateau of Turkey. Phytopathologia Mediterranea 36: 167-181.

Mathre, D.E. (Ed.). (1982). Compendium of barley diseases. APS Press. Minnesota.

Özdemir, H.Y., Karakaya, A., \& Çelik Oğuz, A. (2017). Kırıkkale ilinde buğday ve arpa ekim alanlarında görülen fungal yaprak hastalıklarının belirlenmesi. Bitki Koruma Bülteni 57 (2): 89 112.

Saari, E.E., \& Prescott J.M. (1975). A scale for appraising the foliar intensity of wheat diseases. Plant Disease Reporter 59: 377-380.

TÜiK. (2017). Türkiye İstatistik Kurumu. https://biruni. tuik.gov.tr/medas $/$ ?kn=92\&locale=tr $\quad($ Erișim Tarihi: 28.06.2018)

Yıldırım, A.F., Kınacı, E., Hekimhan, H., \& Çeri, S. (1999). Konya, Karaman, Niğde ve Aksaray yörelerinde tahıllarda önemli hastalıkların durumu ve bunlara dayanıklılık kaynaklarının araștırılması. Orta Anadolu'da Hububat Tarımının Sorunları ve Çözüm Yolları Sempozyumu. 8-11 Haziran 1999, Konya, 404-413.

Zaffarano, P.L., McDonald, B.A., \& Linde, C.C. (2011). Two new species of Rhynchosporium. Mycologia, 103 (1): 195-202.

Zillinsky, F.J. (1983). Common diseases of small grains. A guide to identification. CIMMYT, Mexico. 